\title{
Produtivismo na pós-graduação. Nada é tão ruim, que não possa piorar. É chegada a vez dos orientandos!
}

\author{
Junior Vagner Pereira da Silva* \\ Luiza Lana Gonçalves-Silva** \\ Wagner Wey Moreira***
}

\begin{abstract}
Resumo: Caracterizado como descritivo/exploratório através da análise documental, o estudo examinou os regulamentos/ diretrizes dos programas de mestrado/doutorado em Educação Física, buscando avaliar os possíveis efeitos da política adotada pela Capes sobre as exigências acadêmicas a mestres/doutores. Constatou-se que, além do cumprimento de créditos e elaboração de dissertações/teses, a maioria dos programas exige, também, para titulação, a submissão/ publicação de trabalhos, sobretudo em periódicos Webqualis A1-B5 no mestrado e A1-B1 no doutorado. Conclui-se que as exigências da Capes tem recaído sobre os candidatos a mestre e doutor, pois a publicação de artigos, ao longo do processo, é exigência para titulação.

Palavras-chave: Ciência. Educação. Indicadores de Ciência. Tecnologia e Inovação.
\end{abstract}

\section{INTRODUÇÃO}

Criada em 1951 e, inicialmente, denominada Campanha de Aperfeiçoamento de pessoal do Ensino Superior, a Capes teve como primeira incumbência a formação de corpo docente para atuar no âmbito do ensino superior (erradicação da carência de docentes não titulados em IES públicas do país) (BIANCHETTI, 2011).

\footnotetext{
"Universidade Federal do Mato Grosso do Sul, Campo Grande, MS. E-mail: jr_lazer@yahoo. com.br

"Universidade Federal do Mato Grosso do Sul, Campo Grande, MS. E-mail: luizalana@hotmail. com

"*Universidade Federal do Triângulo Mineiro, Uberlândia, MG. E-mail: wmoreira@ef.uftm.edu.br
} 
A partir de 1976, em decorrência da criação do I Plano Nacional de Pós-Graduação (PNPG) no ano anterior, um sistema de acompanhamento e avaliação da pós-graduação passa a vigorar, imprimindo, desde então, diferentes mudanças na configuração e priorização das ações a serem desenvolvidas pela Capes. Dentre elas, podem ser citadas as ocorridas com o III PNPG (1986-1989), quando a pesquisa passou a ser voltada para ciência e tecnologia e ganhou maior relevância na pós-graduação por acreditar que ela se fazia requisito para assegurar a independência econômica do país, enfatizando, a partir de então, não mais a formação de professores para o ensino superior, mas sim a formação de pesquisadores (KUENZER; MORAES, 2005).

Com essas mudanças nas prioridades e fins da pós-graduação, alterações profundas também ocorreram na política de avaliação dos programas e, por conseguinte, em sua estrutura como um todo. Dentre essas, podem ser citadas: a diminuição do prazo para defesa; as alterações nas exigências para credenciamento de professores e avaliação dos programas, impactando, também, diretamente, os critérios adotados por órgãos de fomentos para financiamento de pesquisa e concessão de bolsas e os critérios adotados em concursos públicos para docência no ensino superior em instituições públicas.

A nova postura assumida pela Capes, órgão regulamentador dos Programas de Pós-graduação Stricto Sensu (PPGSS), levou e tem levado diversos pesquisadores, desde o final da década de 1980, a alertar e pontuar os diferentes problemas que tal política poderia trazer à formação de mestres e doutores e à educação, ganhando destaque, entre eles, as discussões a respeito das novas exigências impostas por sua política.

Em que pese a importância dos tensionamentos feitos pelos estudos disponíveis sobre as implicações das mudanças ocorridas no cenário da pós-graduação brasileira, no que tange aqueles relacionados à Educação Física, não se encontram disponíveis, na literatura, trabalhos que tenham levado em consideração os efeitos diretos aos alunos de mestrado e doutorado, pois a maioria 
das pesquisas gravita em torno das implicações que as exigências trouxeram às subáreas de conhecimento, da desvalorização das publicações em livros em detrimento da supervalorização de artigos e da cobrança exacerbada de publicações a orientadores.

Diante dessa lacuna, a presente investigação teve por objetivo analisar os possíveis efeitos da política adotada pela Capes sobre as exigências acadêmicas na formação de mestres e doutores em PPGSS na subárea Educação Física. Especificamente, buscou analisar os requisitos exigidos (quantidade de créditos; tipos de trabalhos finais a serem entregues; exigência, explícita ou não, de produção científica aos orientandos ao longo do processo de permanência nos programas; tipo de produção valorizada; quantidade e os estratos das publicações) por PPGSS para atribuir o título de mestres e doutores.

\section{Produção do Conhecimento, Pós-graduação E PRODUTIVISMO ACADÊMICO: OS FINS JUSTIFICAM OS MEIOS? AQUILO QUE JÁ ESTÁ RUIM...}

Ao longo da história, diferentes foram os conhecimentos utilizados para explicar as indagações humanas, dentre eles, o senso comum, o filosófico, o teológico e o científico, com elevado destaque ao último (MINAYO, 2004), pois pautava-se em rituais e rigores reconhecidos, em geral, como importantes, caracterizados por um conjunto de cuidados que, se seguidos, assegurariam maior aproximação com a realidade. Essa ideia, nos últimos séculos, se firmou como explicação dominante e intelectualmente mais aceita sobre a realidade e o conhecimento (DEMO, 2009).

Buscando cada qual trazer um tipo de explicação à realidade social e ao conhecimento, por se estruturarem em interesses e visões de mundo divergentes, as diferentes bases teóricas que fundamentam o conhecimento científico se contrariam, se complementam e se sobrepõem. Embora diferentes sejam suas vertentes (empíricoanalítico, materialismo histórico dialético, fenomenológico, estruturalista e pós-modernista), as três primeiras têm ganhado espaço

Movimento, Porto Alegre, v. 20, n. 4, p. 1423-1445, out./dez. de 2014. 
destacado na literatura, pois se constituem bases frequentemente presentes em livros sobre epistemologia e metodologias de pesquisa (TRIVIÑOS, 1987, MINAYO, 2004, DEMO, 2010). Essas concepções também se fazem presentes na sustentação de grande parte de trabalhos e estudos desenvolvidos no âmbito da pós-graduação, embora o método empírico-analítico se lance, presunçosamente, como único capaz de explicar a realidade e produzir conhecimentos verdadeiros (DEMO, 2012), impondo a ditadura do método lógicoexperimental (MORIN, 1996, DEMO, 2005).

Independente da concepção que norteie o pensamento científico, entende-se que a produção desse tipo de conhecimento ocorra por intermédio da pesquisa em seus diferentes gêneros - teórica (construção ou testagem de teorias), metodológica (indagação de instrumentos, elaboração de técnicas e discussão de abordagens teóricas), empírica (mensuração da realidade social) e prática (intervenção na realidade) (MINAYO, 2004). É por intermédio delas que se tem acesso à realidade social, realidade essa que nunca se faz ponto final e é alcançada em sua essência, mas sempre se encontra em contínuo e interminável processo de aproximações (DEMO, 2010).

Sendo a pesquisa razão fundante da vida acadêmica (DEMO, 2011) e, as universidades, local hegemônico de seu desenvolvimento (KUNZ, 2012), seja por intermédio de programas de pós-graduação stricto sensu, pós-graduação lato sensu, iniciação científica, trabalhos finais de graduação ou através de sua estimulação e exercício paralelo à docência, à publicação de dissertações, teses, livros, artigos em periódicos e trabalhos em anais de eventos científicos se constituem formas de circulação do conhecimento produzido, tornando-os públicos.

Embora a produção científica se configure mecanismo de grande relevância, pois brinda a sociedade com o acesso aos avanços, retrocessos e limitações do conhecimento, permitindo que esses sejam questionados, refletidos, reavaliados, como também aplicados em intervenções cotidianas, nas últimas décadas, tem se acompanhado sua acentuada instrumentalização, uma vez que ela

Movimento, Porto Alegre, v. 20, n. 4, p. 1423-1445, out./dez. de 2014. 
passou a ser fortemente utilizada como mecanismo de atribuição de mérito acadêmico, em que a relevância dos trabalhos é aferida por intermédio de medidas bibliométricas, destacando, entre elas, o fator de impacto da revista (número de citações de artigos de uma revista indexada pelo Institute of Scientific Information - ISI em outros periódicos também indexados pelo ISI, sendo o valor obtido pela divisão do número de citações de artigos da revista nos últimos dois anos pelo total de artigos publicados no mesmo período) e o Índice $\mathrm{H}$ do pesquisador (quantidade de artigos publicados por um autor e quantidade de vezes que cada um deles for citado, contabilizando em ambos casos apenas publicações em periódicos indexados no ISI).

Tal condição se mostra mais presente no Brasil a partir do final da década de 1980, quando a política da Capes passou a privilegiar a pós-graduação stricto sensu (PGSS) voltada não mais à formação de professores, mas sim à de pesquisadores, dando ênfase à ciência e à tecnologia, bem como aos mecanismos de avaliação que passaram a ser aperfeiçoados com a valorização da produção científica (KUENZER; MORAES, 2005).

Desde então, gradativamente, essa condição também tem sido incorporada na política adotada pelos órgãos de fomento à pesquisa como mecanismos de concessão de bolsas (produtividade, iniciação científica, mestrado e doutorado), financiamento de pesquisas, apoio à participação em eventos científicos internacionais e nacionais, concursos públicos, dentre outras análises de mérito.

Além de se fazer valer de métrica internacional como fator de impacto, a Capes conta com classificação própria, o Webqualis, que na área de avaliação 21 , composta por programas de pósgraduação que envolvem quatro subáreas de atuação acadêmica e profissional - Educação Física, Fisioterapia, Fonoaudiologia e Terapia Ocupacional -, adota como critério de classificação dos periódicos sua identificação epistemológica com as subáreas e a base de indexação dos periódicos, classificando-os em A1, A2, B1, B2, B3, B4, B5 e C (CAPES, 2013), sendo o ranqueamento no Journal Citation Reports - JCR - requisito mínimo para o alcance de classificação nos estratos mais elevados - A1 e A2.

Movimento, Porto Alegre, v. 20, n. 4, p. 1423-1445, out./dez. de 2014. 
A partir da classificação dada a cada periódico, a Capes tem atribuído um valor quantitativo aos artigos de acordo com o Webqualis em que a publicação ocorre, indo de 100 pontos para aqueles publicados em $\mathrm{A} 1$, a cinco pontos àqueles publicados em $\mathrm{B} 5$ e nenhum ponto sendo atribuído às publicações em revistas em estrato C (CAPES, 2013).

Pautando-se nos mesmos princípios que nortearam o processo de economia mundial - a globalização - a produção e a divulgação científica têm sido fortemente estimuladas na direção da internacionalização, com a valorização da publicação de artigos em periódicos indexados em bases internacionais, sobretudo pelo ISI e ranqueados pelo JCR e, entre os nacionais, os melhores classificados no Webqualis (A1 e A2). São trazidos, para o campo acadêmico, princípios nitidamente característicos do sistema capitalista em que o fator de impacto do periódico e/ou Webqualis se torna moeda corrente para uma demanda cada vez maior de pesquisadores dispostos a alcançá-los. Ou seja, as publicações científicas passam a vigorar com um tipo específico de capital.

Conforme ressalta Oliveira (2006, p. 252-253)

A faceta da reforma neoliberal, que tende a substituir a dádiva pela mercadoria como princípio organizador da ciência, é o peso atribuído à avaliação quantitativa da produtividade dos pesquisadores, individualmente ou agrupados por departamento ou outra unidade institucional de pesquisa. Essa diretriz revela bem a força das concepções neoliberais, uma vez que consegue se impor afrontando instituições muito sólidas a respeito do valor de obras criativas, não só na ciências mas também nas artes. A idéia [sic] de que um cientista que publica duas vezes mais artigos que outro é duas vezes mais produtivo, sem levar em conta a qualidade das obras, é chocante mesmo para o mais elementar senso comum. Essa contradição não é ignorada e motiva a elaboração de formas mais sofisticadas de avaliação, como a que leva em conta o número de citações que cada publicação recebe na literatura especializada. Mas, ainda nesse caso, a ênfase é não apenas no aspecto quantitativo, mas também no requisito de que as

Movimento, Porto Alegre, v. 20, n. 4, p. 1423-1445, out./dez. de 2014. 
quantidades envolvidas devem ser mensuráveis de forma inteiramente objetiva. É difícil explicar de outra maneira tal diretriz, a não ser como um recurso para encaixar a força o conhecimento cientifico no molde da mercadoria.

Diante dessa regra imposta, o sentido primeiro de se fazer pesquisa, produção de conhecimentos e aprendizagens (DEMO, 2009) e suas etapas têm se invertido, pois aquilo que era consequência da pesquisa (produzir e por onde divulgar o conhecimento) passou a ser fim primeiro (qual periódico pode me dar mais pontuação) e aquilo que era fim primeiro da investigação (a descoberta de respostas a problemas que intrigam o pesquisador e por isso o leva a investigar) fica em segundo plano.

[...] A questão crucial sobre o que se está pesquisando/escrevendo é substituída pela pergunta qual o Qualis da revista em que se publica. Os próprios problemas de pesquisa são ultimamente escolhidos por esta questão, ou seja, para mais pontos na Capes [...]. Assim, o problema do sentido, da função e relevância social das pesquisas científicas, bem como as questões sobre que conhecimento e para que formação não fazem mais parte dessas novas preocupações científicas (KUNZ, 2012, p. 9, grifo do autor).

Pautando-se nessa lógica de publicações, os temas a serem investigados, por vezes, não são mais escolhidos com base na necessidade de avanços sobre o conhecimento a respeito de um assunto, mas sim pela maior probabilidade de se publicar em periódicos com alto impacto (MANOEL; CARVALHO, 2011, VITOR-COSTA; SILVA; SORIANO, 2012). Condição similar pode ser observada em estudos internacionais, os quais mostram que, para atender critérios de desempenho profissional e progressão na carreira, cerca de 50,7\% dos pesquisadores entrevistados mudaram de comportamento em relação aos temas e periódicos usados na divulgação do conhecimento (NATURE, 2010).

Qualificar/classificar os pesquisadores de acordo com o meio (livros ou artigos), fator de impacto e Webqualis em que seus trabalhos são publicados tem acentuado os conflitos e problemas

Movimento, Porto Alegre, v. 20, n. 4, p. 1423-1445, out./dez. de 2014. 
no meio acadêmico, trazendo consigo consequências à formação de mestres e doutores. Isso porque a meta de pontuação exigida para credenciamento de docentes/pesquisadores nos PPGSS na subárea Educação Física tem sido cada vez mais alta, e o rol de revistas dispostas a publicar artigos relacionados aos aspectos sociológicos e pedagógicos, por exemplo, é bem inferior em relação ao da biodinâmica, o que leva professores de Educação Física vinculados a essas temáticas buscarem suas inserções em programas de outras áreas, como a educação, considerando o maior número de revistas acessíveis e a valorização de seus trabalhos (BETTI et al., 2004, RIGO; RIBEIRO; HALLAL, 2011).

O permanente enfraquecimento das subáreas pedagógicas e sociológicas tem sido evidenciado em estudos desenvolvidos junto aos PPGSS, indicando que a maioria dos docentes que militam nesses programas na área da Educação Física se encontra vinculada à subárea biodinâmica (60.7\%), o mesmo ocorrendo com os projetos de pesquisas desenvolvidos $(67,4 \%)$ (MANOEL; CARVALHO, 2011). Há, também, uma tendência crescente de credenciamento de orientadores das linhas de pesquisas relacionadas às Ciências Biológicas e da Saúde e, em contrapartida, uma tendência decrescente das relacionadas às Ciências Sociais e Humanas da Educação Física, ocorrendo processo inverso no descredenciamento (RIGO; RIBEIRO; HALLAL, 2011).

A diminuição das linhas e pesquisadores interessados em atuar em orientações de dissertações e teses relacionadas às subáreas pedagógicas e sociológicas pode provocar "efeito dominó", prejudicando sobremaneira os profissionais preocupados em atuar nessas subáreas, como a Educação Física Escolar e o Lazer, gerando, com isso, outros problemas, inclusive o relacionado com a formação insuficiente de recursos humanos para atuarem na docência no ensino superior.

Especificamente para a Educação Física, os danos podem ser ainda maiores, visto que são as subáreas pedagógicas e socioculturais que perfazem a interface entre a Educação Física, a Educação e as Ciências Humanas e Sociais (BETTI et al., 2004).

Movimento, Porto Alegre, v. 20, n. 4, p. 1423-1445, out./dez. de 2014. 
Produtivismo na pós-graduação. Nada é tão ruim que...

\section{Decisões metodológicas}

O estudo se caracteriza como descritivo/exploratório, recorrendo à técnica de análise documental, que se vale de materiais que ainda não receberam tratamento analítico (GIL, 2010).

O objeto de análise foram os regulamentos e diretrizes que regem os programas de pós-graduação na subárea Educação Física em nível de mestrado e doutorado acadêmico, subárea que, até novembro de 2013, se encontrava composta por 26 programas de mestrado e 15 de doutorado, apresentando assimetrias acentuadas quanto a sua distribuição geográfica, sendo o Sudeste e o Sul as regiões com a maior quantidade de cursos credenciados pela Capes, enquanto o Norte figura como a única região sem mestrado e doutorado em Educação Física. No que tange aos Estados, tanto os programas de mestrado quanto os de doutorado se encontram concentrados em São Paulo (figura 1). Ainda, fizeram parte dos documentos analisados os relatórios de avaliação emitidos pela Capes em 2001, 2004, 2007, 2010 e 2013, relativos, respectivamente, aos triênios 1998-2000, 2001-2003, 2004-2006, 2007-2009 e 2010-2012.

Figura 1 - Programas de Mestrado e Doutorado na subárea Educação Física no Brasil
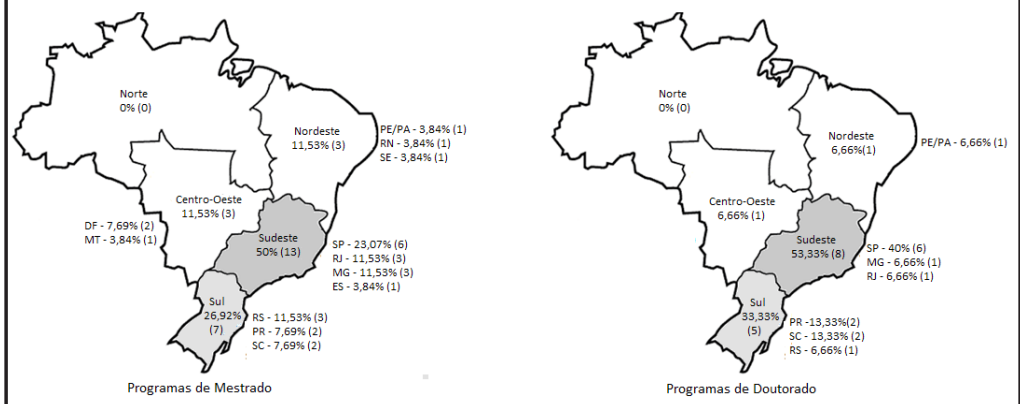

Fonte: Elaborada a partir da relação de cursos recomendados e reconhecidos pela Capes na subárea Educação Física em 2013

Movimento, Porto Alegre, v. 20, n. 4, p. 1423-1445, out./dez. de 2014. 
O contato com os documentos se deu por intermédio do acesso on-line às páginas dos programas e site da Capes. No período de desenvolvimento do estudo (setembro e novembro de 2013), três cursos não disponibilizavam o regulamento e/ou diretrizes do curso on-line. A fim de contemplar os objetivos do estudo, tais documentos foram solicitados às coordenações dos programas via e-mail. Contudo, nenhum dos programas disponibilizou os documentos.

\section{TORNANDO O QUE ESTÁ RUIM AINDA PIOR: ENTRE CRÉDITOS, TRABALHOS FINAIS E PRODUTIVISMO}

No que tange ao modelo de defesa, a maioria dos programas de mestrado (17) e doutorado (10) utiliza a apresentação de dissertações e teses como trabalho final de curso. Contudo, em relação aos critérios adotados para titulação, verifica-se a tendência de, além dos trabalhos finais, exigirem, também, dos alunos, publicações - mestrado (14) e doutorado (10). Quanto ao tipo das publicações exigidas pelos programas que adotam esse critério para titulação, predominam aquelas realizadas no formato de artigo - mestrado (9) e doutorado (6).

Por seu turno, no mestrado, entre os artigos predomina a exigência de publicação em revistas classificadas minimamente no estrato B5 (6), embora em três programas a exigência seja por publicações em estratos superiores a B2 e, em outros dois, acima de B3. Já para o doutorado, dentre os dez programas que exigem publicações de artigos, predomina a exigência de publicações em periódicos classificados em estratos superiores a B1 (4). 
Produtivismo na pós-graduação. Nada é tão ruim que...

Quadro 1 - Exigências acadêmicas e científicas à titulação de mestres

\begin{tabular}{|c|c|c|c|c|c|c|c|}
\hline \multirow{3}{*}{ 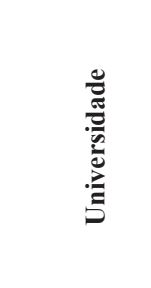 } & \multirow[b]{3}{*}{ 葛 } & \multirow{3}{*}{ 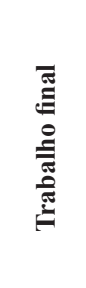 } & \multicolumn{5}{|c|}{ Obrigatoriedade de publicações } \\
\hline & & & \multirow[b]{2}{*}{ 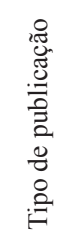 } & \multirow[b]{2}{*}{ 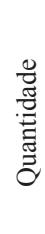 } & \multicolumn{2}{|c|}{ Situação } & \multirow[b]{2}{*}{ 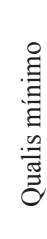 } \\
\hline & & & & & 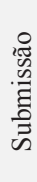 & 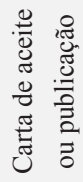 & \\
\hline UNIVERSO & 32 & $\mathrm{D}$ & A & 1 & 1 & - & NE \\
\hline UGF & 27 & D & A & 1 & 1 & - & B2 \\
\hline UNESP-RC & 68 & D/MA & - & - & - & - & - \\
\hline UNIMEP & 30 & $\mathrm{D}$ & - & - & - & - & - \\
\hline UNICSUL & 30 & $\mathrm{D}$ & ALC & 1 & 1 & - & B5 \\
\hline USP & 96 & $\mathrm{D}$ & - & - & - & - & - \\
\hline UNICAMP & 24 & $\mathrm{D}$ & ALC & 1 & 1 & - & B3 \\
\hline USJT & 50 & $\mathrm{D}$ & A & 1 & 1 & - & B5 \\
\hline UFV & 24 & $\mathrm{D}$ & - & - & - & - & - \\
\hline UFTM & 24 & D/MA & - & - & - & - & - \\
\hline UFES & 24 & D & ALC & 1 & 1 & - & B5 \\
\hline UFRGS & 24 & D/MA & - & - & - & - & - \\
\hline UFSM & 24 & $\mathrm{D}$ & A & 1 & 1 & - & B5 \\
\hline UFPEL & 24 & $\mathrm{D}$ & ALC & 1 & 1 & - & $\mathrm{NE}$ \\
\hline UFPR & 28 & D & A & 1 & - & 1 & B3 \\
\hline UEL-UEM & 48 & D & - & - & - & - & - \\
\hline UDESC & 36 & D & A & 1 & - & 1 & B5 \\
\hline UFSC & 30 & D/MA & A & 1 & 1 & - & B5 \\
\hline UCB & 36 & D/MA & ALC & 1 & - & 1 & B2 \\
\hline UFMT & 62 & $\mathrm{D}$ & A & 1 & 1 & - & B2 \\
\hline UPE-UFPB & 24 & D/MA & A & 1 & 1 & - & $\mathrm{NE}$ \\
\hline UFS & 30 & D & - & - & - & - & - \\
\hline UFRN & 48 & D & - & - & - & - & - \\
\hline
\end{tabular}

Fonte: Elaborado a partir dos regulamentos e diretrizes que regiam os programas de pós-graduação (mestrado) na subárea Educação Física em 2013

Legenda: D (dissertação); D/MA (dissertação ou modelo alternativo); A (artigo); ALC (artigos, livros ou capítulos); NE (não especificado).

Movimento, Porto Alegre, v. 20, n. 4, p. 1423-1445, out./dez. de 2014. 
Quadro 2 - Exigências acadêmicas e científicas à titulação de doutores

\begin{tabular}{|c|c|c|c|c|c|c|c|}
\hline \multirow{3}{*}{ 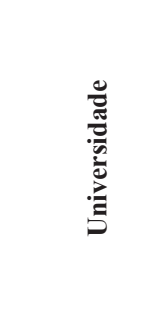 } & \multirow[b]{3}{*}{ 总 } & \multirow{3}{*}{ 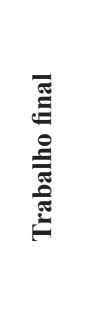 } & \multicolumn{5}{|c|}{ Obrigatoriedade de publicações } \\
\hline & & & \multirow[b]{2}{*}{ 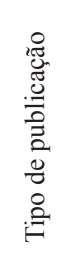 } & \multirow[b]{2}{*}{ 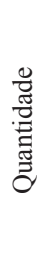 } & \multicolumn{2}{|c|}{ Situação } & \multirow[b]{2}{*}{ 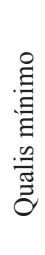 } \\
\hline & & & & & 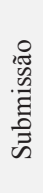 & 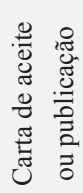 & \\
\hline UGF & 33 & $\mathrm{~T}$ & A & 1 & 1 & & B1 \\
\hline UNESP-RC & 192 & T/MA & - & - & - & - & - \\
\hline UNIMEP & 60 & $\mathrm{~T}$ & - & - & - & - & - \\
\hline UNICSUL & 58 & $\mathrm{~T}$ & ALC & 2 & 2 & & B5 \\
\hline USP & 56 & $\mathrm{~T}$ & - & - & - & - & - \\
\hline UNICAMP & 18 & $\mathrm{~T}$ & ALC & 1 & 1 & & B3 \\
\hline USJT & 100 & $\mathrm{~T}$ & A & 1 & - & 1 & B5 \\
\hline UFRGS & 36 & T/MA & ATC & 1 & - & 1 & $\mathrm{NE}$ \\
\hline UFPR & 42 & $\mathrm{~T}$ & A & 3 & 2 & 1 & B1 \\
\hline UEL-UEM & 84 & $\mathrm{~T}$ & - & - & - & - & - \\
\hline UDESC & 60 & $\mathrm{~T}$ & $\mathrm{~A}$ & 2 & - & 2 & B1 \\
\hline UFSC & 48 & T/MA & A & 1 & 1 & - & B5 \\
\hline $\mathrm{UCB}$ & 58 & $\mathrm{~T} / \mathrm{MA}$ & ALC & 3 & - & 3 & B2 \\
\hline UPE-UFPB & 40 & $\mathrm{~T}$ & A & 2 & 1 & 1 & B1 \\
\hline
\end{tabular}

Fonte: Elaborado a partir dos regulamentos e diretrizes que regiam os programas de pós-graduação (doutorado) na subárea Educação Física em 2013

Legenda: T (tese); T/MA (tese ou modelo alternativo); A (artigo); ALC (artigos, livros ou capítulos); ATC (artigos, textos em anais ou capítulos ); NE (não especificado).

Além de submetidos ao cumprimento de créditos e trabalho final em um curto tempo - dois anos para o mestrado e quatro anos para o doutorado -, por força de regulamento, os estudantes ainda são obrigados a publicar no mínimo um trabalho na maioria dos programas de mestrado (14) e doutorado (10), conforme pode ser observado nos quadros 1 e 2, chegando até mesmo, no caso de dois programas de doutorado, a cobrança de publicação de três artigos. 
Ao analisarmos os quesitos, os itens pertencentes a cada um deles, o peso atribuído e os critérios utilizados pela Capes entre 2001-2013 para avaliação dos PPGSS em Educação Física, nota-se que a exigência de publicações aos alunos de mestrado e doutorado observada neste estudo está intimamente relacionada aos critérios adotados pelo órgão regulador e fomentador da pós-graduação no país para credenciamento, avaliação e classificação dos programas de pós-graduação.

Tal condição pode ser observada na tabela 1 , formulada a partir dos relatórios de avaliação da Capes/área 21 (2001, 2004, 2007, 2010, 2013), que demonstra que o peso atribuído ao quesito corpo discente aumentou de 10\% em 2001 para 30\% em 2007, o mantendo até 2013.

Tabela 1 - Quesitos utilizados pela Capes na avaliação dos programas de Mestrado e Doutorado em Educação Física no período de 2001-2013

\begin{tabular}{|c|c|c|c|c|c|}
\hline \multirow{3}{*}{ Quesitos } & \multicolumn{5}{|c|}{ Ano da avaliação } \\
\hline & 2001 & $2004^{*}$ & 2007 & 2010 & 2013 \\
\hline & \multicolumn{5}{|c|}{ Peso dado à cada quesito $(\%)$} \\
\hline Proposta do programa & $0 \%$ & - & $0 \%$ & $0 \%$ & $0 \%$ \\
\hline Corpo docente & $20 \%$ & - & $30 \%$ & $15 \%$ & $20 \%$ \\
\hline Atividade de pesquisa ${ }^{* *}$ & $10 \%$ & - & & & \\
\hline Atividade de formação** & $15 \%$ & - & & & \\
\hline Corpo discente ${ }^{* * *}$ & $10 \%$ & - & & & \\
\hline Teses e dissertações ${ }^{* * *}$ & $15 \%$ & - & & & \\
\hline Corpo discente, teses e dissertações & & & $30 \%$ & $30 \%$ & $30 \%$ \\
\hline Produção intelectual & $30 \%$ & - & $30 \%$ & $40 \%$ & $40 \%$ \\
\hline Inserção social & & & $10 \%$ & $15 \%$ & $10 \%$ \\
\hline
\end{tabular}

Fonte: Elaborada a partir dos documentos de avaliação trienal da área 21

Legenda: "Não foi atribuído peso a cada um dos itens, mas estabeleceu-se um percentual que os cursos deveriam atingir em cada um dos conceitos atribuídos aos itens; ${ }^{* *}$ Quesitos que foram extintos; ${ }^{* * *}$ Quesitos que foram fundidos - corpo discente, teses e dissertações.

Analisando a questão a partir dos itens que compõem cada um dos quesitos, verifica-se que, embora, a partir de 2007, tenha

Movimento, Porto Alegre, v. 20, n. 4, p. 1423-1445, out./dez. de 2014. 
ocorrido a junção dos quesitos teses e dissertações (até então responsável por um peso de 15\%) com o corpo discente (até então responsável por $10 \%$ ), com essa junção todos os itens que integravam o quesito teses e dissertações foram transformados em apenas um (eficiência do programa na formação de mestres e doutores - tempo de formação de mestres e doutores e percentual de bolsistas da Capes e CNPq titulados).

Quanto às publicações discentes, se, em 2001, a Capes recomendava fortemente a publicação de artigos ou de trabalhos em eventos com ou sem a participação de orientadores, limitandose a um único item do quesito corpo discente, em 2004, passaram a pontuar dois, inovando com a inserção de um item relacionado à integração da pós-graduação e graduação, com atribuição de pontos à participação de alunos da graduação em publicações. Em 2007, além de manter a pontuação para publicações de discentes e egressos dos programas de pós-graduação e alunos da graduação, um novo item foi inserido, passando a pontuar as publicações de artigos relacionados a dissertações e teses de acordo com a classificação dos periódicos no Webqualis.

A hipervalorização da produção científica discente também pode ser observada na evolução do peso dado aos itens do quesito "corpo discente, teses e dissertações", indo de 10\% em 2001 para $60 \%$ em 2008 e $50 \%$ em 2010 e 2013 , o que indica que o aumento ocorrido na valorização desse quesito se deu não em função da junção do corpo discente com teses e dissertações, mas em decorrência do aumento do peso atribuído à produção científica.

A incorporação da obrigatoriedade de publicação de artigos por discentes de mestrado e doutorado atrelada ao orientador busca obter pontuação tanto no quesito "corpo discente, teses e dissertações" quanto "produção científica docente".

Nota-se que, diferentemente dos moldes da pós-graduação vivenciada até a primeira metade da década de 1980, em que pouco ou nada do que ocorria com os orientandos repercutia sobre a vida pessoal, profissional e institucional do orientador, na atualidade, tudo 
o que ocorre na vida acadêmica do orientando repercute no ambiente institucional do orientador e do programa (BIANCHETTI, 2011).

Diante das exigências do órgão regulador, a fim de contemplar e se manterem "vivos" no certame, os programas de mestrado e doutorado em Educação Física vêm incorporando em forma de regulamento e obrigando candidatos a mestre e a doutor a se inserirem na engenhosa lógica do produtivismo acadêmico.

Isso tem feito com que aquilo que já estava ruim, seja em decorrência da cobrança exacerbada de professores para produzirem artigos para sanarem um problema burocrático e não para divulgação de inovações ou oriundo da diminuição do prazo para cumprimento dos créditos e defesa de dissertações e teses, venha se tornando, do ponto de vista formativo, educativo e pedagógico, ainda pior, inserindo mestrandos e doutorandos em um círculo vicioso, pois, conforme expõe Alves, Espindola e Bianchetti (2012, p. 146), "as pressões e exigências emanadas da Capes induziram a adequação dos programas a novos parâmetros de produção e avaliação. No interior dos programas, as mesmas pressões e exigências foram impostas pelos orientadores [...]”".

Dessa forma, "orientadores passam a ser 'gerenciadores de artigos', eles próprios pouco ou nada produzem, mas conseguem 'gerenciar' as produções de seus orientandos de tal forma que consigam boas publicações e os tão almejados pontos na Capes" (KUNZ, 2012, p. 3), assemelhando-se a uma linha de montagem industrial fordista (SOUZA; LUZZI; PEREIRA, 2010).

A respeito desta questão, Manoel e Carvalho (2011, p. 393) expõem que

[...] Os laboratórios de pesquisa assemelham-se a linhas de montagem, expondo a fragmentação da área. Investigações de natureza teórica conceitual têm pouco espaço para veiculação, sobretudo devido às políticas editoriais dos periódicos, as quais estimulam a produção de pesquisas originais que, no final, resultam em um número muito maior de artigos.

Movimento, Porto Alegre, v. 20, n. 4, p. 1423-1445, out./dez. de 2014. 
Posição não diferente é assumida por Kunz (2012, p. 7) quando, ao tratar da produtividade no meio acadêmico, caracterizada por ele como produção da informação, afirma que este tem se configurado em "Fábrica de Textos e Empresa de Publicações".

Constituída num campo de disputa de poder, em que ocorre o tensionamento e luta por espaço entre os diferentes atores envolvidos no processo e a instituição de um antagonismo - órgão reguladorprogramas de pós-graduação, programas de pós-graduaçãopesquisadores, órgãos de fomento-pesquisadores, orientadororientando -, os PPGSS têm feito valer o dito popular "manda quem pode e obedece quem tem juízo", pois, conforme salientam Bianchetti e Machado (2009), só existe um modelo de pós-graduação no país, exigindo que aqueles que desejam usufruir dele se rendam às suas imposições, fazendo com que as consequências recaiam sobre os que dispõem de menor poder, notoriamente, os alunos.

Diante do curto espaço de tempo, aquilo que já era preocupante, pois o tempo de dois anos para o mestrado e quatro para o doutorado, devido às exigências básicas (cumprimento de créditos, elaboração de trabalhos parciais em disciplinas, levantamento bibliográfico, leitura do referencial teórico, treinamento em técnicas de coleta de dados, coleta de dados, apresentação dos resultados e discussão), complexidade do ato de escrever (necessidade de reflexão crítica, desconstrução e reconstrução do conhecimento) e necessidade de se manter vinculado a um emprego para suprir suas necessidades diárias, visto que nem todos dispõem de bolsas de fomento, a exigência de produção de artigos torna a situação dos mestrandos e doutorandos ainda pior. Além de cumprir esses requisitos, pautados na política de produção e buscando atender a Capes, mestrandos e doutorandos se veem no meio do fogo cruzado entre pesquisadores e órgão regulador, recaindo sobre eles os efeitos colaterais. Pressionados pela Capes a manter um corpo docente produtivo, os programas tendem a se apegarem aos pesquisadores em formação (mestrandos e doutorandos) para manterem-se na ativa, exigindo deles a produtividade e alimentando, com isso, um "círculo vicioso" já no processo da formação profissional.

Movimento, Porto Alegre, v. 20, n. 4, p. 1423-1445, out./dez. de 2014. 
Nesse cenário, a produção e a divulgação científica não se encontram mais alinhadas ao fim primeiro da pesquisa - produzir conhecimentos que avancem o estado do saber a respeito de um fenômeno -, mas sim, em muitos casos, como moeda corrente de valoração pessoal do pesquisador, das revistas e dos programas de pós-graduação, pois no meio acadêmico não mais se reconhece o pesquisador pela qualidade de sua produção ou pelo alcance social de suas publicações, mas sim pela quantidade, sobretudo das publicadas em periódicos com fator de impacto.

A respeito dos problemas decorrentes da política de avaliação e financiamento da pós-graduação no país a partir do final da década de 1980, implicações negativas na produção de trabalhos acadêmicos têm sido observadas, dentre elas, a superficialidade dos estudos (KUNZ, 2012), pois dificilmente se vai a fundo a respeito de algo (ALVES; ESPINDOLA; BIANCHETTI; 2012).

A lógica do imediatismo da produção de artigos faz com que características essenciais da investigação se percam, pois, conforme Minayo (1994), essas se configuram (ou nas condições que elas se encontram nos dias atuais, deveriam se configurar) em um processo artesanal, que busca sua fundamentação em conceitos, proposições, métodos, técnicas e na linguagem criativa do pesquisador.

No que tange à criatividade em escrever, cabe ressaltar que ela não brota do nada, mas sim exige conhecimentos por meio de leituras e orientações, exercício do ato de escrever, persistência para transcender barreiras, estando todos esses aspectos articulados à necessidade de tempo hábil para que a ela ocorra sem pressão em demasia.

Bianchetti (2002, p. 3), ao tratar do ato de escrever e da importância de tempo para que haja reflexão sobre o que foi escrito, expõe:

[...]. É o distanciamento que possibilita o admirar, o olhar de outro lugar, o revisitar com outro olhar, ratificando ou retificando o já escrito. Ao serem estabelecidos prazos menores e mais rígidos, esta possibilidade de um texto - educador-daqueleque-o-escreve fica ameaçada. O que é mais grave,

Movimento, Porto Alegre, v. 20, n. 4, p. 1423-1445, out./dez. de 2014. 
no entanto, é que as ameaças em relação ao tempo de conclusão das teses/dissertações não são algo isolado $[\ldots]$.

Se considerarmos que o mestrado tem o tempo regular de dois anos e que diversos periódicos levam de seis meses a um ano para emitir a carta de aceite quando da aprovação do artigo, ao término do primeiro ano do mestrado, nos moldes em que vêm sendo delineados os programas de mestrado e doutorado em Educação Física, obrigatoriamente, o discente já terá que ter submetido seu artigo, algo que, no nosso entender, se configura em mais uma pressão sobre o alunado comprometendo o processo e o significado da formação, trazendo significativos prejuízos ao processo de formação, da produção de conhecimentos críticos e inovadores, capazes de desconstruir e ou substituir os saberes existentes.

É sabido que alternativas têm surgido, como a indução dos candidatos a mestrado e doutorado a cursarem, inicialmente, os programas como alunos especiais e a participarem de trabalhos vinculados ao grupo de pesquisa ao qual está atrelado o seu possível orientador a fim de amenizar os transtornos do curto prazo para conclusão dos cursos (BETTI et al., 2004). Contudo, novamente, o ônus recai sobre os alunos, visto que, por não terem um vínculo formal com o programa, não conseguem afastamento oficial dos empregos para capacitação, como também não podem concorrer à obtenção de bolsas de órgãos de fomentos, inviabilizando, em muitos casos, o acesso a essa qualificação profissional.

\section{Considerações finaIS}

Os resultados obtidos na presente investigação nos permitem concluir que a política avaliativa da Capes para o credenciamento e classificação dos Programas de Pós-graduação Stricto Sensu da subárea da Educação Física penaliza a qualidade da participação discente ao exigir, além do cumprimento dos créditos regulamentares das disciplinas e da redação do trabalho final, a produção de artigos ao longo do processo de formação. 
Tais exigências, por se configuraram em mais uma obrigação e pressão sobre os discentes, visto que o tempo de dois e quatro anos já é pouco, pode contribuir para a estagnação de novos conhecimentos desta área. O processo de formação na pós-graduação stricto sensu, em vez de uma oportunidade de aprofundamento e inovação de conhecimentos, corre o risco de se transformar em produção de trabalhos para o cumprimento de exigências burocráticas, além de oportunizar o desencadeamento de um acentuado desvio de condutas éticas na produção do conhecimento, como plágio, publicações em empilhamento, fatiamento das publicações, autocitação descontextualizada, dentre outros possíveis problemas.

O que se está defendendo aqui não é a extinção da divulgação do conhecimento por meio de publicações em artigos; pelo contrário, essa etapa se configura como um importante momento do ciclo da produção do conhecimento. Porém, se adverte sobre as implicações que tal ordem pode trazer à qualidade da formação dos futuros mestres e doutores.

Em que pese a importância da divulgação do conhecimento produzido ao longo de um processo, entendemos que essa deve ser uma consequência do trabalho desenvolvido e ser realizado, posteriormente, ao tempo estabelecido para cumprimento de créditos e estudos do referencial teórico e elaboração do trabalho final. Dessa forma, publicar pesquisas não pode ser considerado um fim em si mesmo, uma instrumentalização da produção científica, adotada como mais uma exigência à titulação.

Ademais, cabe advertir que nem todos os discentes que adentram a pós-graduação almejam se tornar pesquisadores, pois também podem estar em busca de conhecimentos com objetivos de aplicá-los, desenvolvê-los e reformulá-los no seu fazer pedagógico escolar, sendo assim penalizados, ao longo de sua formação, por terem que, além de se dedicar ao cumprimento de créditos em disciplinas e elaboração do trabalho final (dissertação ou teses), produzir artigos para atender uma exigência burocrática. Por consequência, isso implica, também, em redução de tempo

Movimento, Porto Alegre, v. 20, n. 4, p. 1423-1445, out./dez. de 2014. 
que, consequentemente, diminui as possibilidades do discente de desenvolver maior aprofundamento de teorias filosóficas, sociológicas e políticas sobre seu objetivo de estudo, colaborando, em parte, para que reflexões aprofundadas não ocorram.

Productivism at graduate studies: things are never so bad they can't be made worse. the turn of graduate students!

Abstract: This descriptive/exploratory conducted through document analysis examined the regulations/guidelines of Doctoral and Master's Degree programs in Physical Education, seeking to evaluate the possible effects of the policy adopted by CAPES on academic requirements to masters/doctoral degree holders. It found that, in addition to academic credits and dissertations/theses, most programs also require submission/publication of papers, especially on Webqualis A1-B5 journals for master programs and on A1-B1 for doctoral programs. It concludes that CAPES's requirements have fallen on master and doctoral candidates since publishing articles throughout the process is required to receive titles.

Keywords: Science. Education. Science Indicators. Technology and Innovation.

El productivismo en la postgraduación. nada es tan malo que
no se pueda empeorar. jes la hora de los aprendices!
Resumen: Caracterizado como descriptivo/exploratorio, a través
de estudio de análisis documental examinando las regulaciones/
lineamientos de los programas de maestría/doctorado en
Educación Física, tratando de evaluar los posibles efectos de la
política adoptada por la CAPES sobre los requisitos académicos
para maestro/doctor. Se descubrió que, además de los créditos
académicos y la preparación de disertaciones/tesis, la mayoría de
los programas también requieren valoración para la presentación/
publicación de los trabajos, especialmente en WebQualis journals
A1-B5 en maestría y doctorado en A1-B1. Llegamos a la conclusión
de que los requisitos de la CAPES ha pesado sobre los candidatos
a la maestría y el doctorado, ya que la publicación de artículos
en todo el proceso de titulación es requisito para la obtención del
título.
Palabras clave: Ciencia. Educación. Indicadores de Ciencia,
Tecnología e Innovación.

Movimento, Porto Alegre, v. 20, n. 4, p. 1423-1445, out./dez. de 2014. 


\section{REFERÊNCIAS}

ALVES, Vânia Maria; ESPINDOLA, Isabel Cristina Pitz; BIANCHETTI, Lucídio. A relação orientandor-orientando na pós-graduação stricto sensu no Brasil: a autonomia dos discentes em discussão. Revista Educação em Questão, Natal, v. 43, n. 29, p. 135-156, maio/ago. 2012. Disponível em: <http://incubadora.ufrn.br/ index.php/req/article/view/571/484>. Acesso em: 9 nov. 2013.

BETTI, Mauro et al. A avaliação da educação física em debate: implicações para a subárea pedagógica e sociocultural. Revista Brasileira de Pós-Graduação, Brasília, v. 1, p. 183-194, nov. 2004. Disponível em: <http://www2.capes.gov.br/ rbpg/images/stories/downloads/RBPG/Vol.1 2 nov2004/183 194 avaliacao educacaofisica_debate.pdf>. Acesso em: 20 set. 2013.

BIANCHETTI, Lucídio. Condições de trabalho e repercussões pessoais e profissionais dos envolvidos com a pós-graduação stricto sensu: balanço e perspectivas. Linhas Críticas, Brasília, v. 17, n. 34, p. 439-460, set./dez. 2011. Disponível em: <http://www.redalyc.org/articulo.oa?id=193522070002>. Acesso em: 20 set. 2013.

BIANCHETTI, Lucídio. O desafio de escrever dissertações/teses: como incrementar a quantidade e manter a qualidade com menos tempo e menos recursos? In: BIANCHETTI, Lucídio; MACHADO, Ana Maria Netto. A bússola do escrever. Florianópolis: Editora da UFSC, 2002. p. 165-186.

BIANCHETTI, Lucídio; MACHADO, Ana Maria Netto. Publicar \& Morrer!? Análise do impacto das políticas de pesquisa e pós-graduação na constituição do tempo de trabalho dos investigadores. Educação, Sociedade e Culturas, Porto, n. 28, p.5369, jul. 2009. Disponível em: <http://www.fpce.up.pt/ciie/revistaesc/ESC28/28 lucidio.pdf>. Acesso em: 15 jul. 2013.

BRASIL. Lei no 10.197, de 14 de fevereiro de 2001. Acresce dispositivos ao DecretoLei no 719 , de 31 de julho de 1969, para dispor sobre o financiamento a projetos de implantação e recuperação de infra-estrutura de pesquisa nas instituições públicas de ensino superior e de pesquisa, e dá outras providências. Diário Oficial [da] República Federativa do Brasil, Brasília, n. 34-E, p. 4-6, 16 fev. Seção 1.

COORDENAÇÃO DE APERFEIÇOAMENTO DE PESSOAL DE NÍVEL SUPERIORCAPES. Relatório da área 21: Avaliação trienal 2013. Disponível em: <http://www. capes.gov.br/images/stories/download/avaliacaotrienal/Docs_de area/Educação Física doc area e comissão att08deoutubro.pdf>. Acesso em: 10 out. 2013.

DEMO, Pedro. Dureza: pobreza política de mulheres pobres. Campinas: Autores Associados, 2005.

DEMO, Pedro. Introdução à metodologia da ciência. 2. ed. São Paulo: Atlas, 2010.

DEMO, Pedro. Metodologia científica em ciências sociais. 3. ed. rev. e aum. São Paulo: Atlas, 2012.

Movimento, Porto Alegre, v. 20, n. 4, p. 1423-1445, out./dez. de 2014. 
DEMO, Pedro. Metodologia do conhecimento científico. São Paulo: Atlas, 2009.

DEMO, Pedro. Pesquisa: princípio científico e educativo. 14. ed. São Paulo: Cortez, 2011.

KUENZER, Acacia Zeneida; MORAES, Maria Célia Marcondes de. Temas e tramas na pós-graduação em educação. Educação e Sociedade, Campinas, v. 26, n. 93, p. 1341-1362, set./dez. 2005. Disponível em: <http://www.scielo.br/scielo. php?pid=S0101-73302005000400015\&script=sci_arttext>. Acesso em: 10 jul. 2013.

KUNZ, Elenor. Pós-graduação em Educação Física no Brasil: o fenômeno da hiperprodutividade e formação cultural. Revista Kinesis, Santa Maria, v. 30, n. 1, p. 1-13, jul. 2012. Disponível em: <http://cascavel.ufsm.br/revistas/ojs-2.2.2/index. php/kinesis/article/view/5717/3403>. Acesso em: 15 jul. 2013.

GEOCAPES. Dados estatísticos. Disponível em: <http://geocapes.capes.gov.br/ geocapesds/>. Acesso em: 2 fev. 2013.

GIL, Antônio Carlos. Métodos e técnicas de pesquisa social. 6. ed. São Paulo: Atlas, 2010.

MANOEL, Edson de Jesus; CARVALHO, Yara Maria de. Pós-graduação na educação física brasileira: a atração (fatal) para a biodinâmica. Educação e Pesquisa, São Paulo, v. 37, n. 2, p. 389-406, maio/ago. 2011. Disponível em: <http:// www.scielo.br/scielo.php?script=sci arttext\&pid=S1517-97022011000200012\&lng =en\&nrm=iso >. Acesso em: 9 nov. 2013.

MINAYO, Maria Cecília de Souza. O desafio do conhecimento: pesquisa qualitativa em saúde. 8. ed. São Paulo: Hucitec, 2004.

MINAYO, Maria Cecília de Souza. Ciência, técnica e arte: o desafio da pesquisa social. In: MINAYO, Maria Cecília de Souza et al. Pesquisa social: teoria, método e criatividade. Petrópolis: Vozes, 1994. p. 9-29.

MORIN, Edgar. Ciência com consciência. Rio de Janeiro: Bertrand Brasil, 1996.

NATURE. Metrics survey results. Nature, London, 2010. Disponível em: <http:// www.nature.com/nature/newspdf/metrics_survey.pdf>. Acesso em: 29 out. 2013.

OLIVEIRA, Marcos Barbosa de. Desmercantilizar a tecnociência. In: SANTOS, Boaventura de Souza (Org.). Conhecimento prudente para uma vida decente: um discurso sobre as ciências revisitado. São Paulo: Cortez, 2006.

RIGO, Luís Carlos; RIBEIRO, Gabriela Maria; HALLAL, Pedro Curri. Unidade na diversidade: desafios para a Educação Física no Século XXI. Revista Brasileira de Atividade Física \& Saúde, Pelotas, v. 16, n. 4, p. 339-345, abr./jun. Disponível em: <http://www.sbafs.org.br/ artigos/482.pdf>. Acesso em: 15 jul. 2013.

SOUZA, Eduardo Rumenig; LUZZI, Alexandre; PEREIRA, Benedito. O fordismo acadêmico na educação física. Revista Brasileira de Ciência e Esporte, 
Florianópolis, v. 32, n. 2/4, p. 43-57, dez. 2010. Disponível em: <http://www.scielo. br/pdf/rbce/v32n2-4/04.pdf>. Acesso em: 30 set. 2013.

TRIVIÑOS, Augusto Nibaldo Silva. Introdução à pesquisa em ciências sociais: a pesquisa qualitativa em educação. São Paulo: Atlas, 1987.

VITOR-COSTA, Marcelo; SILVA, Priscila Maia da; SORIANO, Jeane Barcelos. A avaliação da produtividade em pesquisa na Educação Física: reflexões sobre algumas limitações dos indicadores bibliométricos. Revista Brasileira de Educação Física e Esporte, São Paulo, v. 26, n. 4, p. 581-597, out./dez. 2012. Disponível em: <http://www.scielo.br/pdf/rbefe/v26n4/v26n4a05.pdf>. Acesso em: 30 set. 2013.

\section{Endereço para correspondência}

Junior Vagner Pereira da Silva

Rua Padre João Crippa, 3.506 - Edifício Dubai - Apto 603

Monte Castelo - Campo Grande - MS - CEP 79010-180 